\title{
Bone grafting material in combination with Osteogain for bone repair: a rat histomorphometric study
}

\author{
Yufeng Zhang ${ }^{1}$ • Dai Jing ${ }^{1}$ • Daniel Buser ${ }^{2}$ • Anton Sculean ${ }^{3}$. \\ Fatiha Chandad $^{4} \cdot$ Richard J. Miron ${ }^{1,2,3,4}$
}

Received: 25 March 2015 / Accepted: 3 July 2015 / Published online: 15 July 2015

(C) Springer-Verlag Berlin Heidelberg 2015

\begin{abstract}
Objectives Enamel matrix derivative (EMD) has been successfully used for the regeneration of periodontal tissues including new cementum, periodontal ligament, and alveolar bone. Combination of EMD with bone grafting materials has however generated variable clinical results. Recently, we have demonstrated that a new formulation of EMD in a liquid carrier system (Osteogain ${ }^{\circledR}$ ) has improved physicochemical properties for the adsorption of EMD to a bone grafting material. The aim of the present study was to investigate the regenerative potential of Osteogain ${ }^{\circledR}$, in combination with a bone graft, on new bone formation in a rat femur defect model. Materials and methods Fifty-four critically sized femur defects $(3 \mathrm{~mm}$ in diameter) were created bilaterally in 27 rats and treated following the group allocation: (1) drilled unfilled control, (2) a natural bone mineral (NBM), and (3) NBM + Osteogain ${ }^{\circledR}$. All defects were histologically analyzed at 2, 4, and 8 weeks after surgical intervention. Micro-CT analysis,
\end{abstract}

Yufeng Zhang and Dai Jing contributed equally to this work.

Yufeng Zhang

zyf@whu.edu.cn

Richard J. Miron

richard.miron@zmk.unibe.ch

1 The State Key Laboratory Breeding Base of Basic Science of Stomatology (Hubei-MOST) and Key Laboratory of Oral Biomedicine Ministry of Education, School and Hospital of Stomatology, Wuhan University, Wuhan, China

2 Department of Oral Surgery and Stomatology, School of Dental Medicine, University of Bern, Bern, Switzerland

3 Department of Periodontology, School of Dental Medicine, University of Bern, Bern, Switzerland

4 University of Laval, Dental School, Quebec City, Canada hematoxylin and eosin (H\&E) staining, and Safranin O staining were performed to quantify new bone formation.

Results Significantly more new bone formation was observed in defects treated with NBM + Osteogain ${ }^{\circledR}$ at both 4 and 8 weeks when compared to NBM alone and the control unfilled defects $(P<0.05)$. Histologically, the formation of more mature mineralized bone with the presence of osteocytes were found more commonly in defects treated with Osteogain ${ }^{\circledR}+$ NBM at 8 weeks post-healing when compared to NBM alone. Conclusions The present study demonstrate that Osteogain ${ }^{\circledR}$ in combination with a bone grafting material improves the speed and quality of new bone formation in rat osseous defects.

Clinical relevance Future clinical research are now warranted to fully characterize the benefits of Osteogain ${ }^{\circledR}$, a new formulation of enamel matrix proteins delivered in liquid formation when used in combination with a bone grafting material.

Keywords Enamel matrix derivative (EMD) - Emdogain . Natural bone mineral $\cdot$ BioOss $\cdot$ Bone grafting materials

\section{Introduction}

One modality that has been used to manage a variety of periodontal disorders is the use of an enamel matrix derivative (EMD) harvested from developing porcine teeth [1-4]. It has previously been shown that the proteins found in EMD have a significant influence on cell behavior of many cell types by mediating cell attachment, spreading, proliferation, and survival, as well as expression of transcription factors, growth factors, cytokines, extracellular matrix constituents, and other molecules involved in the regulation of bone remodeling [5]. Amelogenin is the major component of EMD, a family of hydrophobic proteins that account for over $95 \%$ of the total 
protein content [6]. Other proteins that exist in the enamel matrix include enamelin, ameloblastin (also called amelin or sheathlin), amelotin, apin, and various proteinases [7, 8].

For years, EMD has been packaged in a polyglycolic acid (PGA) carrier under the trademark name Emdogain ${ }^{\circledR}$. In order to improve the regenerative potential of Emdogain ${ }^{\circledR}$, various attempts have been made to combine it with a bone grafting material to prevent flap collapse and improve blood clot stability [9]. While a variety of clinical trials have shown positive effects for a combination of Emdogain ${ }^{\circledR}+$ grafting material when compared to treatment with either Emdogain ${ }^{\circledR}$ alone or grafting materials alone, others have failed to show such an advantage [9-16].

Recent research from our laboratory has demonstrated that the adsorption of EMD to bone grafting material varies significantly between grafting materials [17]. Furthermore, the use of Emdogain ${ }^{\circledR}$, although ideal for root surface adsorption, displayed drastically increased thickness of coating of enamel matrix proteins to the bone grafting surface which were easily dissolved following a simple PBS rinse. Contrarily, the use of EMD in a liquid formulation exhibited more favorable surface coating by demonstrating (a) an increase and more complete surface loading of porous graft materials and (b) tighter and more stable surface coating with enamel matrix proteins [17]. The physicochemical properties of EMD were then modified to deliver it through stable liquid formulation, specifically for combination with bone grafting particles, with better adsorption properties (Wangnerud et al. 2015, currently under review). This new formulation of EMD, called Osteogain ${ }^{\circledR}$, demonstrates similar effects on osteoblast and periodontal ligament (PDL) cell proliferation and differentiation when compared to Emdogain ${ }^{\circledR}$. Furthermore, its combination with a bone grafting material increased a wide variety of osteoblast transcription factors, differentiation factors, cytokines, and proteins when compared to bone grafting material alone (Miron et al. 2015, currently in review).

Thus, the aim of the present study was to investigate the regenerative potential of Osteogain ${ }^{\circledR}$ when combined with a bone grafting material on bone defects. Femur defects created in rats were filled with either a natural bone mineral (NBM) alone or NBM + Osteogain ${ }^{\circledR}$ and compared to control blank defects.

\section{Materials and methods}

\section{Animal experiments}

Twenty-seven male Wistar rats ( 8 weeks of age, $180-200$-g weight) were used. All animal handling and surgical procedures were in accordance with the policies of the Ethics Committee for Animal Research, Wuhan University, China (ethical approval number 2011038). The animals were housed in individual wire cages in a temperature- and humiditycontrolled room $\left(20-25{ }^{\circ} \mathrm{C}\right.$ and $60 \pm 5 \%$ relative humidity) with a 12-h light/dark cycle and allowed food and water ad libitum. All animals were allowed to acclimate with the laboratory environment for 1 week before surgical procedures were carried out. All operations were carried out under sterile conditions with gentle surgical techniques. The animals were administered intramuscular injections of penicillin (NCPC; $400,000 \mathrm{IU} / \mathrm{ml}, 0.1 \mathrm{ml} / \mathrm{kg}$ day) at the time of surgery and once daily for the next 3 days. No significant pre-operation or postoperation fractures were produced.

Femur defect drilling was performed under general anesthesia by intraperitoneal injection of sodium pentobarbital (Merck, Darmstadt, Germany; $40 \mathrm{mg} / \mathrm{kg}$ body weight) as previously described [18-20]. A linear skin incision of approximately $1 \mathrm{~cm}$ in the distal femoral epiphysis was made bilaterally, and blunt dissection of the muscles was performed to expose the femoral condyle [21, 22]. Then, a 2.2-mm-diameter anteroposterior bicortical channel was created perpendicular to the shaft axis to remove cancellous bone, by using a trephine bur at a slow speed irrigated under saline solution to avoid thermal necrosis. The drilled holes were rinsed with saline solution in order to remove bone fragments from the cavity. An equal amount of implant materials $(0.1 \mathrm{~g}$ per hole $)$ was then gently placed to fill the grilled defects according to group allocation: drilled control, NBM, and NBM + Osteogain ${ }^{\circledR}$, respectively. The concentration of enamel matrix proteins (EMPs) for Osteogain ${ }^{\circledR}$ is $30 \mathrm{mg} / \mathrm{ml}$, and EMDs are dissolved with acetic acid to a $\mathrm{pH}$ ranging from 4 to 4.5 . Nine rats (18 defects) were randomly assigned to three groups at each time point $(6$ defects per group per time point $\times 2$ time points for a total of 12 defects total per group). Each animal received two types of treatments such as control unfiled defects and NBM alone, or control defects and NBM + Osteogain ${ }^{\circledR}$, or NBM and NBM + Osteogain ${ }^{\circledR}$ at each time point. Nine animals were euthanized at each of the two time points.

At each time point, 2, 4, and 8 weeks after femur surgery, animals were sacrificed accordingly. All femurs were harvested and assigned to micro-computerized tomography (microCT) and histological evaluation.

\section{Micro-CT analysis}

The samples were fixed in $4 \%$ formaldehyde for $24 \mathrm{~h}$ at room temperature. A $\mu$-CT imaging system ( $\mu$-CT50, Scanco Medical, Basersdorf, Switzerland) was used to evaluate new bone formation within the defect region. All samples were placed in a custom-made holder to ensure that the long axis of the drilled channel was oriented perpendicular to the axis of X-ray beam. All samples were calibrated by performing a scans with identical parameters at $55 \mathrm{kV}$ and $114 \mathrm{~mA}$ with a thickness of $0.048 \mathrm{~mm}$ per slice in medium-resolution mode, 
1024 reconstruction matrix, and 200-ms integration time. A Gaussian filter ( $\operatorname{sigma}=0.8$ and $\operatorname{support}=1$ ) was used to remove noise. The mineralized bone tissue was differentially segmented to exclude the nonmineralized tissue with a fixed threshold (value $=190$ ). A series of slices starting at a distance of $1 \mathrm{~mm}$ proximal from the end of the growth plate with a length of $2 \mathrm{~mm}$ were chosen for the evaluation. For evaluation of bone regeneration within the defect, the central 2-mmdiameter region of the 2.5-mm-diameter defect was defined by drawing circular contour as area of measurement per slice, thus to obtain a consistent volume of interest (VOI) and to avoid including the native bone margins. All 3D images were generated by the built-in software of the $\mu$-CT as previously described [18].

\section{Histological preparation}

After fixation, femoral condyles were decalcified in $10 \%$ ethylene diamine tetraacetic acid (EDTA) for 6 weeks, dehydrated in a series of graded concentration of ethanol from 70 to $100 \%$ and embedded in paraffin. For the paraffin samples, longitudinal serial sections, $4 \mu \mathrm{m}$ thick, were cut and mounted on poly-lysine-coated microscope slides. For descriptive histology, hematoxylin and eosin (H\&E) staining, and Safranin O staining (Sigma \#S2255; Sigma-Aldrich, St. Louis, MO, USA) were performed according to manufacturer's protocol. Specimens were examined under microscopic light using Olympus DP72 microscope (Olympus Corporation, Tokyo, Japan).

Qualification of the regenerated bone was performed according to H\&E and Safranin O staining by using Image-Pro Plus 6.0 software (Media Cybernetics, USA). Areas of newly formed bone, which acquired a red color in H\&E-stained sections and a bluish-green stain in Safranin O-stained sections, were delineated manually and then calculated as the percentage of new bone area in total cross-sectional area [(bone area/ total area) $\times 100 \%$ as previously described [19, 23-25]. The central region of the $2.5-\mathrm{mm}$-diameter defect was defined by analyzing a circular contour as area of measurement per slice, thus to obtain a consistent volume of interest and to avoid including the native bone margins. To validate the results, each experiment was repeated at least three times under calibrated measurements with the operator blinded to the surgical technique. Safranin O staining was used to quantitatively investigate the dynamic degradation process of NBM and NBM + Osteogain ${ }^{\circledR}$ particles.

\section{Statistical analysis}

All statistical analyses were performed by using Statistical Package for the Social Sciences (SPSS) 17.0 software (SPSS, Chicago, IL). Percentage of new bone formation was expressed as mean \pm standard deviation and analyzed using one-way ANOVA with post hoc test. $p<0.05$ was considered as statistically significant difference.

\section{Results}

\section{Outcomes by micro-CT}

Micro-CT reconstruction was used to visualize the ability of NBM alone or in combination with Osteogain ${ }^{\circledR}$-(NBM + Osteogain ${ }^{\circledR}$ ) to influence new bone formation (Fig. 1). As can be seen from the unfilled control groups, little to no bone formation was observed at 2 weeks post-implantation (Fig. 1a) with little new bone formation occurring at the cortex of defects at 4 and 8 weeks post-implantation (Figs. 1b, c). Defects filled with NBM material initially demonstrate a large filled area of mineralized tissue since NBM grafting particles are mineralized (Fig. 1d). Increase in bone formation was observed at 4 and 8 weeks post-implantation (Fig. 1e, f). A similar trend is observed for defects filled with NBM + Osteogain ${ }^{\circledR}$ when compared to NBM alone (Fig. 1g-i). Due to the inability to quantify solely mineralized tissues produced from new bone (as opposed to the mineralized tissue contained in NBM particles), a conventional histological approach was utilized to quantify new bone formation using morphohistometric analysis (Figs. 2, 3, 4, and 5).

\section{Evaluation of new bone formation}

During all experiments, no signs of foreign body inflammation were observed. At each time point of 2, 4, and 8 weeks, representative sections of $H \& E$ staining and Safranin O staining are presented in Figs. 2, 3, 4, and 5, respectively, showing the interface between the tissue and the implanted graft.

After 2 weeks, regenerated new bone and fibrous tissue were observed in treatment groups filled with NBM or $\mathrm{NBM}+$ Osteogain ${ }^{\circledR}$ (Fig. 2d, g), while the mesenchymal cells derived from marrow cavity occupied the entire cavity of the drilled control group (Fig. 2a). No visible difference in new bone formation was observed between NBM and NBM + Osteogain ${ }^{\circledR}$ groups at 2 weeks. At 4 weeks post-operation, minimal bone formation in the control samples was observed with large voids still present (Fig. 2b). In contrast, at 4 weeks post-implantation, new bone formation, in both NBM precoated with Osteogain ${ }^{\circledR}$ and NBM only filled defects increased significantly (Fig. 2e, h). In morphology, mature bone lacuna with the presence of osteocytes in the NBM + Osteogain ${ }^{\circledR}$ _ filled defects were present when compared to NBM alone. At 8 weeks post-operation, the continual progression of new bone formation in the defects was observed around NBM particles precoated with Osteogain ${ }^{\circledR}$ (Fig. 2f, i). More newly formed bone and less fibrous tissue in the NBM + Osteogain ${ }^{\circledR}$-filled defect was observed when compared to 
Fig. 1 Micro-CT images demonstrating the morphology and defects either left unfilled $(\mathbf{a}-\mathbf{c})$, filled with NBM $(\mathbf{d}-\mathbf{f})$, or filled with $\mathrm{NBM}+$ Osteogain $^{\circledR}$ (g-i). Scale bar, $2 \mathrm{~mm}$

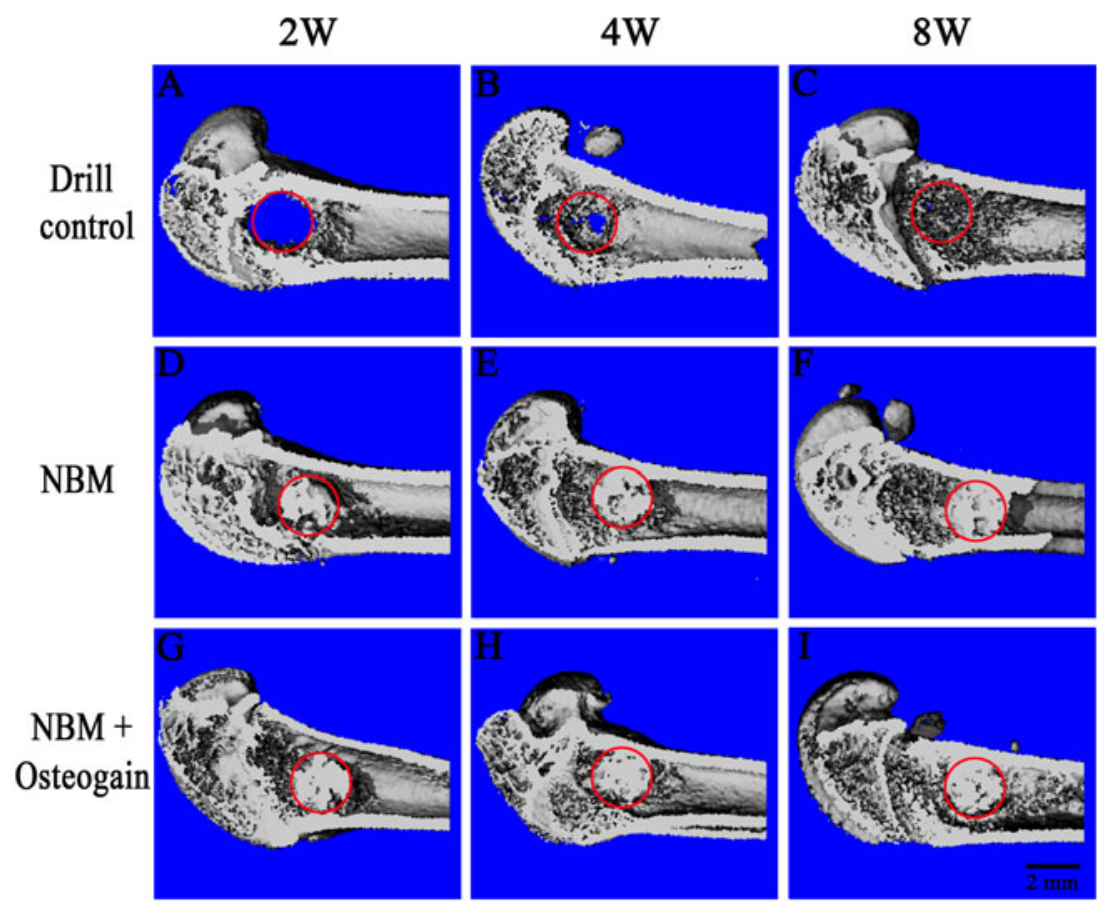

NBM alone at 8 weeks post-implantation. Control defects that were left unfilled were still void of any substantial amount of regenerated new bone formation at 8 weeks of healing (Fig. 2c).

The new bone formation in the defects in all treatment groups was quantitatively assessed from sections of H\&E staining at each time point of 2, 4, and 8 weeks (Fig. 3). Significantly much more newly formed bone was observed around both NBM + Osteogain ${ }^{\circledR}$ and NBM alone when compared to the drilled control group at all time points $(p<0.05)$. Although no significant difference between NBM + Osteogain ${ }^{\circledR}$ and NBM alone could be observed at 2 weeks post-operation, statistical analysis revealed that new bone formation was significantly higher in the NBM + Osteogain ${ }^{\circledR}$ group at 4 and 8 weeks when compared to NBM alone $(p<0.05)$.

Safranin O staining was utilized to quantify newly formed bone by delineating manually and calculating the percentage of new bone area in total cross-sectional area (Figs. 4 and 5). Consistent with the quantitative outcomes from sections of H\&E staining, significantly higher new bone formation was observed in NBM + Osteogain ${ }^{\circledR}$ group when compared to control unfilled group at each time point $(p<0.01)$. Although no significant difference between NBM + Osteogain ${ }^{\circledR}$ and
Fig. 2 Representative sections of $H \& E$ staining demonstrate the healing of defects left unfilled $(\mathbf{a}-\mathbf{c})$, filled with NBM $(\mathbf{d}-\mathbf{f})$, or filled with $\mathrm{NBM}+$ Osteogain $^{\circledR}$ (g-i) at 2, 4, and 8 weeks postimplantation. More newly formed bone can be observed in groups treated with NBM and NBM

+ Osteogain ${ }^{\circledR}$ when compared to control drill defects at each time point of 2,4 , and 8 weeks. Triangle, newly formed bone; asterisk, filled graft; scale bar, $100 \mu \mathrm{m}$

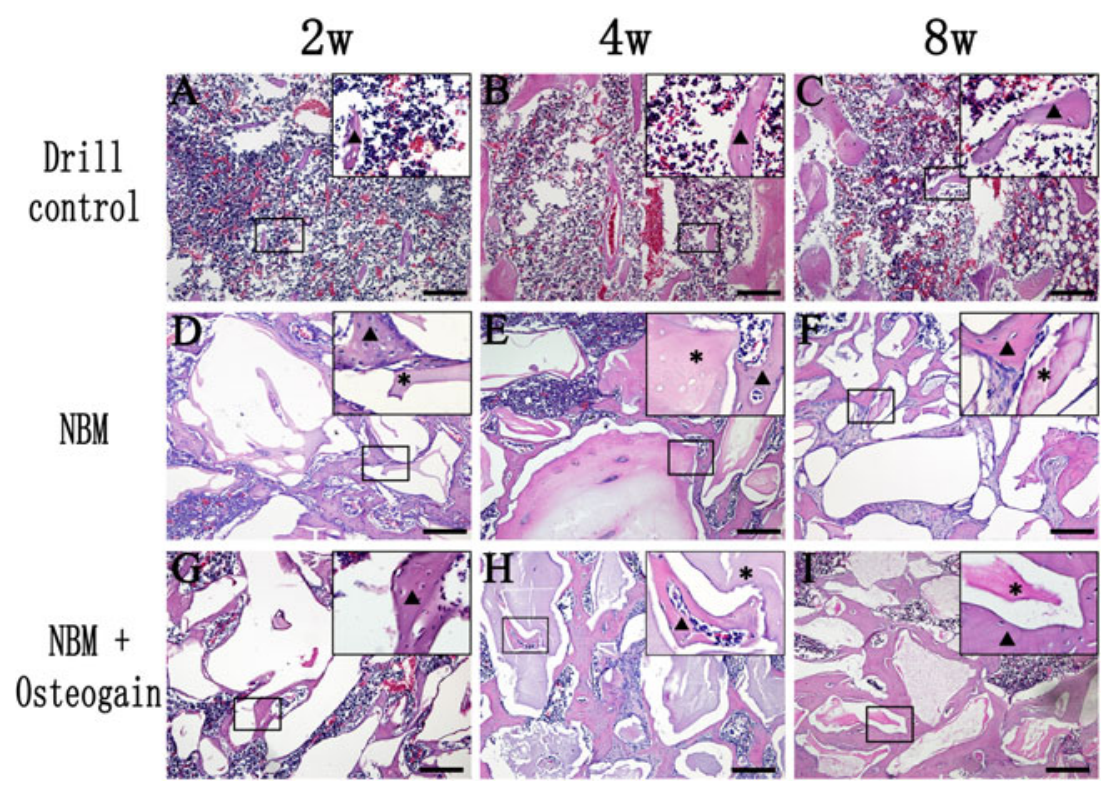




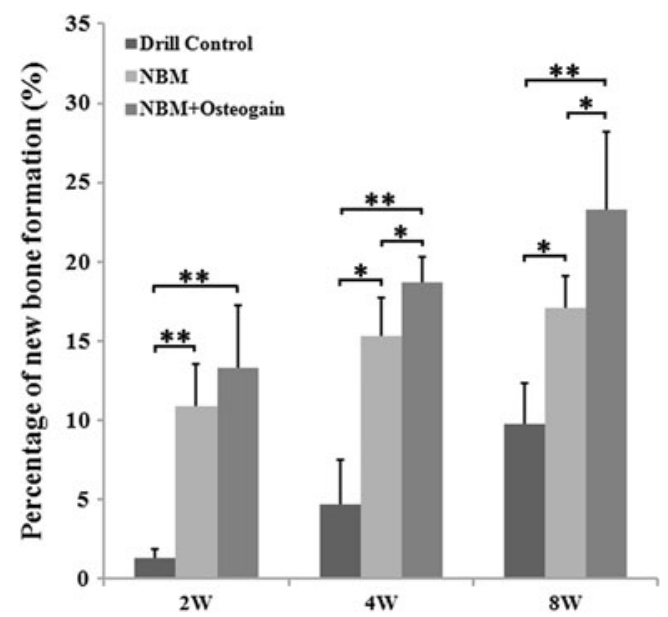

Fig. 3 Percentage of new bone formation measured by analysis of the H\&E staining images. Significantly higher new bone formation was observed in NBM + Osteogain ${ }^{\circledR}$ group when compared to control unfilled and NBM alone groups at 4 and 8 weeks post-implantation. ${ }^{*} p<0.05,{ }^{* *} p<0.01$

NBM alone could be observed at 2 weeks post-surgery, significantly more newly formed bone was detected in the NBM + Osteogain ${ }^{\circledR}$ group at 4 and 8 weeks when compared to NBM alone $(p<0.05)$.

\section{Discussion}

The aim of the present study was to investigate the potential of Osteogain $^{\circledR}$ in combination with a bone grafting material. Although the accumulated data until now has demonstrated strong evidence that EMD enhances periodontal regeneration, the effects on bone formation has primarily been limited to intrabony defects [1]. Our group has previously demonstrated that EMD in combination with a NBM led to an increase in

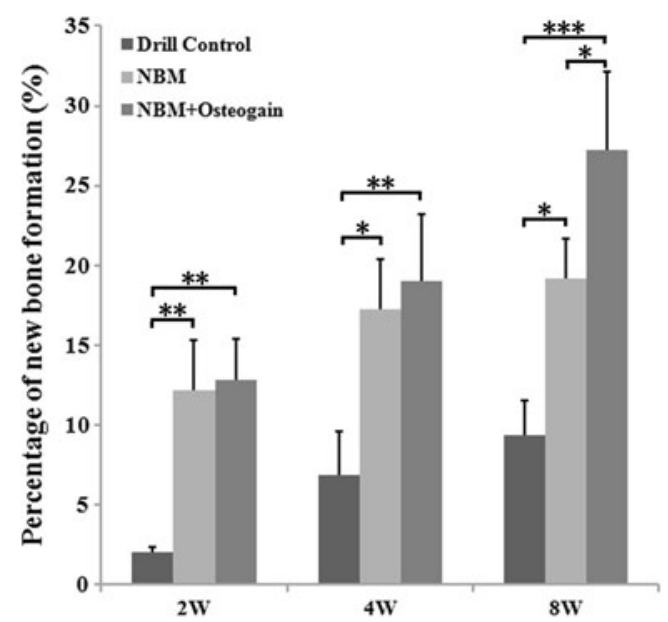

Fig. 5 Percentage of new bone formation measured by analysis of the Safranin O staining images. Significantly higher new bone formation was observed in NBM + Osteogain ${ }^{\circledR}$ group when compared to control unfilled group at each time point and NBM alone group at 4 and 8 weeks postimplantation. ${ }^{*} p<0.05 ; * * p<0.01 ; * * * p<0.001$

osteoblast proliferation and differentiation, as well as upregulated a number of key cytokines, growth factors, and their associated receptors, transcription factors, and osteoblast differentiation markers $[26,27]$. Despite these in vitro results, there remains a variety of mixed results over the clinical efficacy of combining Emdogain ${ }^{\circledR}$ with a bone grafting material for clinical use. While some clinical trials have demonstrated that the combination provides additional regeneration, others have failed to show any additional benefit when compared to bone grafting material used alone or Emdogain ${ }^{\circledR}$ used alone $[9,12,14,28,29]$.

Due to these large variation in reported data, our group recently investigated the adsorption of EMD to grafting particles and observed significantly altered levels of amelogenin adsorption to the various grafting materials used [17].
Fig. 4 Representative sections of Safranin O staining demonstrating the healing of treatment at 2,4 , and 8 weeks post-implantation. Triangle, newly formed bone; asterisk, filled graft; scale bar, $100 \mu \mathrm{m}$

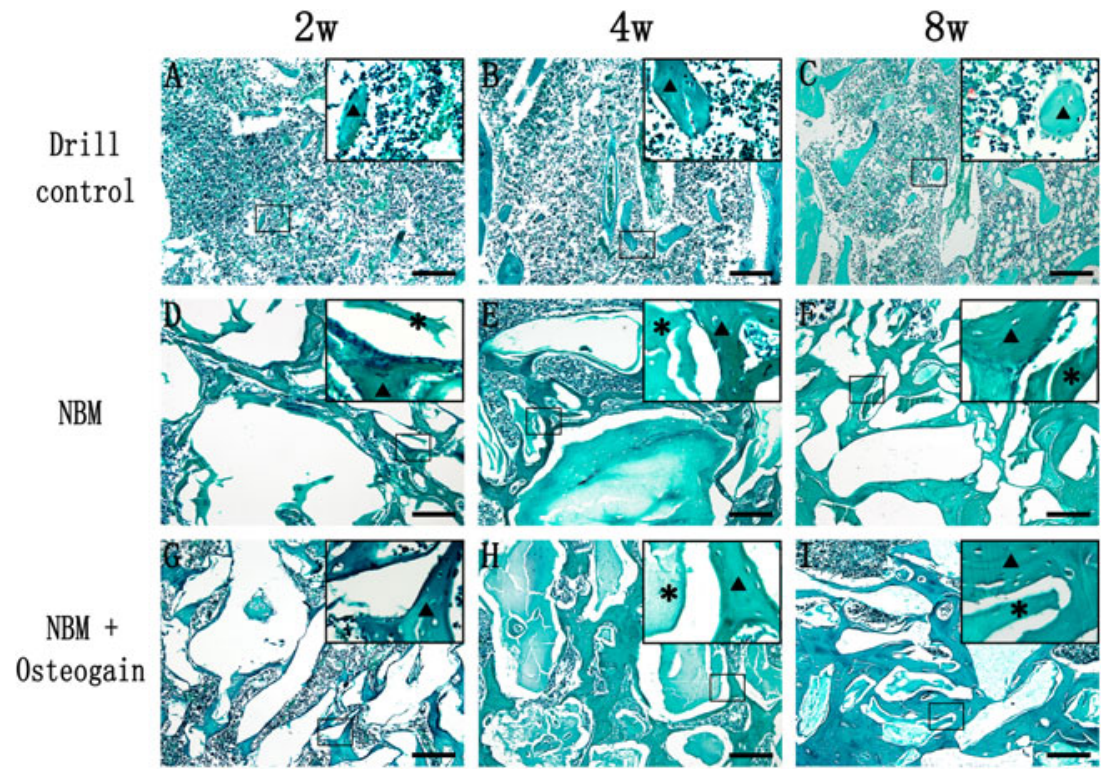


Interestingly, the delivery of EMD in liquid formulation improved the adsorption to bone grafting surface when compared to Emdogain ${ }^{\circledR}$ gel. For these reasons, the development of a new carrier for EMD with better physicochemical properties was undertaken specifically for combination with bone grafting material.

In this study, the femur defect model was utilized to fully characterize the regenerative potential of Osteogain ${ }^{\circledR}$ in combination with a bone grafting material. The femur is an area with a high number of mesenchymal progenitor cells located in the bone marrow cavity. Since the effects of EMD target cells early in their differentiation process [30], the use of the present model system was sensitive to any regenerative advantages that Osteogain ${ }^{\circledR}$ could therefore produce. In our previous study on bone formation using NBM in a femur defect, we avoided the use of micro-CT to investigate new bone formation as it had an inability to accurately quantify new bone formation due to high mineral content already present in NBM. For these reasons, we used a conventional histological approach to quantify new bone formation. The results from histological quantification of new bone formation demonstrated that Osteogain ${ }^{\circledR}$ significantly increased new bone formation at 4 and 8 weeks post-implantation when compared to NBM particles alone and drilled control defects. Furthermore, the combination of Osteogain ${ }^{\circledR}+$ NBM further provided a higher number of osteocytes embedded within the new bone matrix around grafting particles.

The key components improving new bone formation in the present study were the effects of enamel matrix proteins which have been shown to affect new bone formation under various models and also utilizing various carrier systems [20, 31-35]. In a classical study by Boyan et al., it was shown that although EMD does not possess osteoinductive potential, it possessed osteopromotive benefits when it is combined with active demineralized freeze-dried bone allografts (DFDBA) and resulted in enhanced bone induction [31]. Furthermore, recent research from Cochran's group has provided evidence for angiogenic properties of enamel matrix proteins which may substantially improve vascularization and future wound healing [36]. Our group has also previously characterized the combination of EMD delivered in a PGA carrier on new bone formation in the same animal model where it was also found that EMD improved new bone formation [6]. Thus, it remains to be evaluated what effect Osteogain ${ }^{\circledR}$ may have in the context to the previously published data and more importantly what effect the carrier of EMD may have on its osteopromotive potential for future bone defects with complicated anatomical defects.

\section{Conclusions}

Within the limits of the present study, these findings indicate that the combination of a NBM with Osteogain ${ }^{\circledR}$ was able to improve bone formation when compared to control unfilled and NBM alone defects. Furthermore, it was demonstrated that Osteogain ${ }^{\circledR}$, a new formation of EMD with better physicochemical properties, was able to significantly enhance mature new bone formation by demonstrating signs of osteocyte lacunae embedded within the new bone matrix. Future clinical research is necessary to fully elucidate the advantages of Osteogain $^{\circledR}$ in combination with a bone graft material as a new carrier system for enamel matrix proteins.

Conflict of interest The study was funded by Straumann AG, Basel, Switzerland. The NBM bone graft was provided by Geistlich Pharma AG, Switzerland, and Osteogain ${ }^{\circledR}$ was provided by Straumann AG, Switzerland. No further conflict of interest exists.

\section{References}

1. Sculean A, Alessandri R, Miron R, Salvi G, Bosshard DD (2011) Enamel matrix proteins and periodontal wound healing and regeneration. Clin Adv Periodontics 1:101-117

2. Aspriello SD, Ferrante L, Rubini C, Piemontese M (2011) Comparative study of DFDBA in combination with enamel matrix derivative versus DFDBA alone for treatment of periodontal intrabony defects at 12 months post-surgery. Clinical oral investigations 15:225-232

3. Pietruska M, Pietruski J, Nagy K, Brecx M, Arweiler NB, Sculean A (2012) Four-year results following treatment of intrabony periodontal defects with an enamel matrix derivative alone or combined with a biphasic calcium phosphate. Clinical oral investigations 16 : 1191-1197. doi:10.1007/s00784-011-0611-2

4. Oortgiesen DA, Meijer GJ, Bronckers AL, Walboomers XF, Jansen JA (2013) Regeneration of the periodontium using enamel matrix derivative in combination with an injectable bone cement. Clin Oral Investig 17:411-421. doi:10.1007/s00784-012-0743-Z

5. Bosshardt DD (2008) Biological mediators and periodontal regeneration: a review of enamel matrix proteins at the cellular and molecular levels. J Clin Periodontol 35:87-105. doi:10.1111/j.1600051X.2008.01264.X

6. Lyngstadaas SP, Wohlfahrt JC, Brookes SJ, Paine ML, Snead ML, Reseland JE (2009) Enamel matrix proteins; old molecules for new applications. Orthodontics \& Craniofac Res 12:243-253. doi:10. $1111 / j .1601-6343.2009 .01459 . x$

7. Margolis HC, Beniash E, Fowler CE (2006) Role of macromolecular assembly of enamel matrix proteins in enamel formation. $\mathrm{J}$ Dent Res 85:775-793

8. Bartlett JD, Ganss B, Goldberg M, Moradian-Oldak J, Paine ML, Snead ML, Wen X, White SN, Zhou YL (2006) 3. Protein-protein interactions of the developing enamel matrix. Curr Top Dev Biol 74:57-115. doi:10.1016/s0070-2153(06)74003-0

9. Miron RJ, Guillemette V, Zhang Y, Chandad F, Sculean A (2014) Enamel matrix derivative in combination with bone grafts: a review of the literature. Quintessence Int 45:475-487. doi:10.3290/j.qi. a31541

10. Guida L, Annunziata M, Belardo S, Farina R, Scabbia A, Trombelli L (2007) Effect of autogenous cortical bone particulate in conjunction with enamel matrix derivative in the treatment of periodontal intraosseous defects. J Periodontol 78:231-238. doi:10.1902/jop. 2007.060142

11. Kuru B, Yilmaz S, Argin K, Noyan U (2006) Enamel matrix derivative alone or in combination with a bioactive glass in wide 
intrabony defects. Clin Oral Investig 10:227-234. doi:10.1007/ s00784-006-0052-5

12. Velasquez-Plata D, Scheyer ET, Mellonig JT (2002) Clinical comparison of an enamel matrix derivative used alone or in combination with a bovine-derived xenograft for the treatment of periodontal osseous defects in humans. J Periodontol 73:433-440. doi:10. 1902/jop.2002.73.4.433

13. Lekovic V, Camargo PM, Weinlaender M, Nedic M, Aleksic Z, Kenney EB (2000) A comparison between enamel matrix proteins used alone or in combination with bovine porous bone mineral in the treatment of intrabony periodontal defects in humans. J Periodontol 71:1110-1116. doi:10.1902/jop.2000.71.7.1110

14. Zucchelli G, Amore C, Montebugnoli L, De Sanctis M (2003) Enamel matrix proteins and bovine porous bone mineral in the treatment of intrabony defects: a comparative controlled clinical trial. J Periodontol 74:1725-1735. doi:10.1902/jop.2003.74.12. 1725

15. Gurinsky BS, Mills MP, Mellonig JT (2004) Clinical evaluation of demineralized freeze-dried bone allograft and enamel matrix derivative versus enamel matrix derivative alone for the treatment of periodontal osseous defects in humans. J Periodontol 75:13091318. doi:10.1902/jop.2004.75.10.1309

16. Trombelli L, Farina R (2008) Clinical outcomes with bioactive agents alone or in combination with grafting or guided tissue regeneration. J Clin Periodontol 35:117-135. doi:10.1111/j.1600-051X. 2008.01265.x

17. Miron RJ, Bosshardt DD, Buser D, Zhang Y, Tugulu S, Gemperli A, Dard M, Caluseru OM, Chandad F and Sculean A (2015) Comparison of the capacity of enamel matrix derivative-gel and enamel matrix derivative in liquid formulation to adsorb to bone grafting materials. J Periodontol:1-18. doi: 10.1902/jop.2015. 140538

18. Cheng N, Dai J, Cheng X, Li S, Miron RJ, Wu T, Chen W, Zhang Y, Shi B (2013) Porous CaP/silk composite scaffolds to repair femur defects in an osteoporotic model. J Mater Sci Mater Med 24:19631975. doi:10.1007/s10856-013-4945-y

19. Wei L, Miron RJ, Shi B, Zhang Y (2013) Osteoinductive and osteopromotive variability among different demineralized bone allografts. Clin Implant Dent Relat Res. doi:10.1111/cid.12118

20. Miron RJ, Wei L, Bosshardt DD, Buser D, Sculean A, Zhang Y (2014) Effects of enamel matrix proteins in combination with a bovine-derived natural bone mineral for the repair of bone defects. Clinical oral investigations 18:471-478. doi:10.1007/s00784-0130992-5

21. Zhang Y, Cheng N, Miron R, Shi B, Cheng X (2012) Delivery of PDGF-B and BMP-7 by mesoporous bioglass/silk fibrin scaffolds for the repair of osteoporotic defects. Biomaterials 33:6698-6708. doi:10.1016/j.biomaterials.2012.06.021

22. Zhang Y, Wu C, Luo T, Li S, Cheng X, Miron RJ (2012) Synthesis and inflammatory response of a novel silk fibroin scaffold containing BMP7 adenovirus for bone regeneration. Bone 51:704-713. doi:10.1016/j.bone.2012.06.029

23. Liao L, Yang S, Miron RJ, Wei J, Zhang Y, Zhang M (2014) Osteogenic properties of PBLG-g-HA/PLLA nanocomposites. PLoS One 9, e105876. doi:10.1371/journal.pone.0105876

24. Wei L, Ke J, Prasadam I, Miron RJ, Lin S, Xiao Y, Chang J, Wu C and Zhang Y (2014) A comparative study of Sr-incorporated mesoporous bioactive glass scaffolds for regeneration of osteopenic bone defects. Osteoporosis international : a journal established as result of cooperation between the European Foundation for Osteoporosis and the National Osteoporosis Foundation of the USA 25:2089-2096. doi: 10.1007/s00198-014-2735-0

25. Zhang Y, Wei L, Miron RJ, Shi B, Bian Z (2014) Anabolic bone formation via a site specific bone targeting delivery system by interfering with semaphorin 4D expression. J Bone Miner Res: Off J Am Soc Bone Min Res. doi:10.1002/jbmr.2322

26. Miron RJ, Bosshardt DD, Hedbom E, Zhang Y, Haenni B, Buser D, Sculean A (2012) Adsorption of enamel matrix proteins to a bovine-derived bone grafting material and its regulation of cell adhesion, proliferation, and differentiation. J Periodontol 83:936947. doi:10.1902/jop.2011.110480

27. Miron RJ, Bosshardt DD, Zhang Y, Buser D, Sculean A (2013) Gene array of primary human osteoblasts exposed to enamel matrix derivative in combination with a natural bone mineral. Clin Oral Investig 17:405-410. doi:10.1007/s00784-012-0742-0

28. Scheyer ET, Velasquez-Plata D, Brunsvold MA, Lasho DJ, Mellonig JT (2002) A clinical comparison of a bovine-derived xenograft used alone and in combination with enamel matrix derivative for the treatment of periodontal osseous defects in humans. J Periodontol 73:423-432. doi:10.1902/jop.2002.73.4.423

29. Sculean A, Chiantella GC, Windisch P, Gera I, Reich E (2002) Clinical evaluation of an enamel matrix protein derivative (Emdogain) combined with a bovine-derived xenograft (Bio-Oss) for the treatment of intrabony periodontal defects in humans. Int $\mathrm{J}$ Periodontics Restorative Dent 22:259-267

30. Miron RJ, Caluseru OM, Guillemette V, Zhang Y, Gemperli AC, Chandad F, Sculean A (2013) Influence of enamel matrix derivative on cells at different maturation stages of differentiation. PLoS One 8, e71008. doi:10.1371/journal.pone.0071008

31. Boyan BD, Weesner TC, Lohmann CH, Andreacchio D, Carnes DL, Dean DD, Cochran DL, Schwartz Z (2000) Porcine fetal enamel matrix derivative enhances bone formation induced by demineralized freeze dried bone allograft in vivo. J Periodontol 71:1278-1286. doi:10.1902/jop.2000.71.8.1278

32. Sakallioglu U, Acikgoz G, Ayas B, Kirtiloglu T, Sakallioglu E (2004) Healing of periodontal defects treated with enamel matrix proteins and root surface conditioning-an experimental study in dogs. Biomaterials 25:1831-1840

33. Stout BM, Alent BJ, Pedalino P, Holbrook R, Gluhak-Heinrich J, Cui Y, Harris MA, Gemperli AC, Cochran DL, Deas DE, Harris SE (2014) Enamel matrix derivative: protein components and osteoinductive properties. J Periodontol 85:e9-e17. doi:10.1902/ jop.2013.130264

34. Kawana F, Sawae Y, Sahara T, Tanaka S, Debari K, Shimizu M, Sasaki T (2001) Porcine enamel matrix derivative enhances trabecular bone regeneration during wound healing of injured rat femur. Anat Rec 264:438-446

35. Sawae Y, Sahara T, Kawana F, Sasaki T (2002) Effects of enamel matrix derivative on mineralized tissue formation during bone wound healing in rat parietal bone defects. J Electron Microsc 51: 413-423

36. Kauvar AS, Thoma DS, Carnes DL, Cochran DL (2010) In vivo angiogenic activity of enamel matrix derivative. J Periodontol 81: 1196-1201. doi:10.1902/jop.2010.090441 